Revue belge de géographie

\title{
Rosière S., Le nettoyage ethnique - terreur et peuplement
}

Paris, Ellipses, Coll. Carrefours, les dossiers, 2006, 293 p.

\section{J. Vandeburie}

\section{OpenEdition}

\section{Journals}

Édition électronique

URL : http://journals.openedition.org/belgeo/11787

DOI : $10.4000 /$ belgeo. 11787

ISSN : 2294-9135

Éditeur :

National Committee of Geography of Belgium, Société Royale Belge de Géographie

Édition imprimée

Date de publication : 31 décembre 2006

Pagination : 498-500

ISSN : 1377-2368

Référence électronique

J. Vandeburie, « Rosière S., Le nettoyage ethnique - terreur et peuplement », Belgeo [En ligne], 4 | 2006, mis en ligne le 31 octobre 2013, consulté le 22 septembre 2020. URL : http://journals.openedition.org/ belgeo/11787; DOI : https://doi.org/10.4000/belgeo.11787

Ce document a été généré automatiquement le 22 septembre 2020.

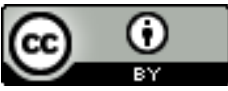

Belgeo est mis à disposition selon les termes de la licence Creative Commons Attribution 4.0 International. 


\section{Rosière S., Le nettoyage ethnique - terreur et peuplement}

Paris, Ellipses, Coll. Carrefours, les dossiers, 2006, 293 p.

\section{J. Vandeburie}

\section{RÉFÉRENCE}

Rosière S., Le nettoyage ethnique - terreur et peuplement, Paris, Ellipses, Coll. Carrefours, les dossiers, $293 \mathrm{p}$.

1 Le dernier ouvrage de Stéphane Rosière est un excellent livre, bien documenté et agréablement écrit, à la fois de géographie politique et de géopolitique. Sur base d'une distinction faite par l'auteur dans un précédent ouvrage $^{1}$, la géographie politique considère l'espace comme cadre. Stéphane Rosière s'attarde donc sur les fondements théoriques entourant la notion de nettoyage ethnique en géographie. Le corpus théorique est issu des théories du système-monde et emploie les concepts de Centre et Périphérie, familiers aux géographes s'intéressant aux questions économiques et politiques. Mais Stéphane Rosière sait en faire un usage modéré et en montrer les limites lorsqu'il propose une carte de synthèse des trois «mondes" du nettoyage ethnique (carte 21, p. 276), c'est-à-dire le nettoyage de modelage territorial ou « Core Cleansing» (Europe, Afrique du Nord, Proche et Moyen-Orient, Monde Indien, Indochine et Chine), le nettoyage de front pionnier (Amériques, Sibérie, Indonésie et Océanie) et le nettoyage de prédation (Afrique sub-saharienne). C'est aussi un ouvrage traitant de géopolitique, car l'auteur s'emploie à dénoncer les manoeuvres des appareils politiques (souvent les Etats) qui créent la peur, manipulent les peuples pour s'assurer le contrôle d'un territoire et d'un peuple. Les phénomènes de statogenèse et de translation territoriale sont étroitement liés au nettoyage ethnique ainsi que Stéphane Rosière le montre avec - entre autres - les exemples yougoslaves, pakistanais ou israélien. La distinction opératoire de l'auteur ${ }^{2}$ est de considérer ici l'espace comme 
enjeu. L'espace est dans ce cas le territoire, occupé par un peuple dont la diversité est l'objet du nettoyage ethnique.

2 Dans son introduction, l'auteur nous renseigne que "le nettoyage résulte d'une combinaison des différentes formes de modification coercitive de peuplement (...) fondées sur l'expulsion et l'extermination (p. 5)». La distinction avec la notion de génocide est rapidement observée : «le génocide a pour finalité le peuple, le nettoyage ethnique a pour finalité le territoire (p. 6) ». Si cette distinction simple est plus amplement développée dans la suite de l'ouvrage, elle campe la dimension géographique du nettoyage ethnique, expression dont le sens actuel est forgé lors de l'éclatement de l'exYougoslavie et de la guerre en Bosnie. En s'attardant sur les modalités de coercition du peuplement, l'auteur distingue selon la terminologie anglo-saxonne les ex-politics et les in-politics. Dans le premier cas, la fusion des peuples est considérée comme impossible et le nettoyage comme nécessaire, se développe alors d'une politique d'exclusion, d' expulsion et d'extermination. Dans le second cas, l'homogénéisation est basée sur la violence, niant différence, altérité et imposant l'intégration forcée dans le corps national. L'Etat français s'est ainsi basé sur l'école, la conscription et l'administration pour assimiler les Basques, Bretons et Corses.

3 Dans un premier chapitre théorique, Stéphane Rosière revient sur les besoins de classement de la population par les autorités politiques lors de la construction de l'EtatNation sous son angle territorial. L'auteur définit alors l'ethnie comme tout groupe distinct d'autre(s) par l'existence de marqueurs ethniques (qui recouvrent des aspects linguistiques, religieux, culturels et sociaux). Stéphane Rosière fait le choix argumenté - ici suffisamment convaincant - de considérer les termes ethnie et nation comme équivalents.

4 Le second chapitre revient sur les origines de la pratique à travers l'exemple exyougoslave. La notion de pureté est discutée mais au-delà des idéologies, l'auteur insiste sur le développement nécessaire de capacité d'ingénierie ethnique et de l'irruption de considérations stratégiques afin de rendre le territoire militairement défendables et parfois économiquement viables. Dans la continuité, le troisième chapitre est consacré aux acteurs du nettoyage et sa mise en oeuvre par le haut (Etat) et par le bas (les citoyens), la peur, la violence et la manipulation étant présent à tous les étages.

$5 \quad$ Le chapitre IV s'attarde sur les logiques territoriales. En référence avec les théories du système-monde, les nettoyages peuvent relever (1) de logiques territoriales, liées au découpage du monde en territoire politiques, ou (2) de logiques spatiales, liées aux qualités mêmes de l'espace et à ses richesses, cette logique ayant plus d'importance dans la périphérie. Ce parallèle entre nettoyage et Etat-Nation est un développement qui, sans toutefois le faire, évoque les théories géopolitiques classiques. Stéphane Rosière tisse alors sa typologie, distinguant parmi les logiques territoriales, les nettoyages de modelage territorial et les translations territoriales (sécurisation des périphéries). Les logiques spatiales incluent quant à elles les nettoyages de prédation et les nettoyages de contrôle social.

6 Les exemples sont développés de manière semblable des chapitres cinq à quinze. Ils sont d'autant plus convaincants que l'auteur n'essaie pas de forcer la démonstration des similitudes de ces exemples; au contraire, en soulignant leurs diversités, il met en évidence l'universalité de certains mécanismes géopolitiques parmi lesquels le 
nettoyage ethnique. Des exemples connus (Bosnie, Arménie, partition des Indes, etc.) côtoient des cas moins médiatiques (Bhoutan, Iles Salomon).

7 Les conclusions sont organisées autour de cinq bilans. Du point de vue méthodologique, le débat est lancé autour de cette typologie. On retiendra que «tout nettoyage dispose d'une dimension de prédation dans la mesure où les acteurs accaparent toujours quelque chose: territoire, position sociale, sinon biens de leur victime, etc. La prédation est donc une constante et le nettoyage peut toujours être analysé comme une forme de redistribution violente des richesses. De même, la dimension de contrôle social est aussi valable dans tous les cas. La création d'un Etat ou la translation de ses frontières correspondent toujours à l'affirmation d'un contrôle sur un territoire, et donc sur une population (p. 272)». Les conclusions démographiques dressent un bilan humain partiel et mis en comparaison. Le bilan géographique (illustré par la carte 21) situe en quelque sorte le nettoyage par rapport aux théories géopolitique classiques, sa description (soulignée par l'auteur) étant valable à l'échelle planétaire. Les conclusions politiques illustrent la juste interprétation du nettoyage comme «aboutissement et processus fondateur [de l'EtatNation] (p. 278)».

Enfin, sans prétendre à l'exhaustivité (remarque p. 272), Stéphane Rosière ouvre de manière convaincante et rigoureuse - dans ses conclusions épistémologiques - ce champ d'étude, la géographie de la violence, aux géographes. Afin de nourrir la réflexion, on ne peut que conseiller la lecture de ses autres publications ${ }^{3}$.

\section{NOTES}

1. Stéphane Rosière (2003). Géographie politique et géopolitique, une grammaire de l'espace politique, Paris, Ellipses, coll. Université Géographie. L'auteur se base sur les travaux de Raymond Aron considérant l'espace comme cadre, enjeu et théâtre.

2. Idem.

3. Stéphane Rosière (2004), "Le nettoyage ethnique - approche géographique ", Geographica Helvetica, 3, pp. 227-237.

(2005a), « Nettoyage ethnique, violences politiques et peuplement », Revue géographique de l'Est, $X L V, 1$, pp. 5-12.

(2005b), "La communauté internationale face au nettoyage ethnique », in SANGUIN A.-L., CHAVENEAU-LEBRUN E. et CATTARUZZA A. (dir.), L'ex-Yougoslavie dix ans après Dayton. De nouveaux Etats entre déchirements communautaires et intégration européenne, Paris, L'Harmattan, pp. 28-37.

(2005c), «La diversité ethnique et le maillage administratif des Etats », Cahiers de Géographie du Québec, 49, 137, pp. 207-224. 